\title{
Exit From the High Street An Exploratory Study of Sustainable Fashion Consumption Pioneers
}

\author{
Bly, Sarah; Gwozdz, Wencke; Reisch, Lucia
}

Document Version

Accepted author manuscript

Published in:

International Journal of Consumer Studies

DOI:

10.1111/ijcs.12159

Publication date:

2015

License

Unspecified

Citation for published version (APA):

Bly, S., Gwozdz, W., \& Reisch, L. (2015). Exit From the High Street: An Exploratory Study of Sustainable Fashion Consumption Pioneers. International Journal of Consumer Studies, 39(2), 125-135.

https://doi.org/10.1111/ijcs.12159

Link to publication in CBS Research Portal

\section{General rights}

Copyright and moral rights for the publications made accessible in the public portal are retained by the authors and/or other copyright owners and it is a condition of accessing publications that users recognise and abide by the legal requirements associated with these rights.

Take down policy

If you believe that this document breaches copyright please contact us (research.lib@cbs.dk) providing details, and we will remove access to the work immediately and investigate your claim. 


\section{Exit From the High Street: An Exploratory Study of Sustainable Fashion Consumption Pioneers}

\section{Sarah Bly, Wencke Gwozdz, and Lucia Reisch}

Journal article (Post print version)

This is the peer reviewed version of the following article: Exit From the High Street :

An Exploratory Study of Sustainable Fashion Consumption Pioneers. / Bly, Sarah;

Gwozdz, Wencke; Reisch, Lucia. In: International Journal of Consumer Studies, Vol.

39, No. 2, 2015, p. 125-135, which has been published in final form at http://dx.doi.org/10.1111/ijcs.12159.

This article may be used for non-commercial purposes in accordance with Wiley Terms and Conditions for Self-Archiving.

Uploaded to Research@CBS: January २०17 


\section{Exit from the High Street}

An exploratory study of sustainable fashion consumption pioneers

Sarah Bly ${ }^{1}$, Wencke Gwozdz ${ }^{2}$, Lucia A. Reisch 3

${ }^{1}$ Department of Intercultural Communication and Management (ICM), Copenhagen Business School, Frederiksberg, Denmark

2 ICM, Copenhagen Business School, Frederiksberg, Denmark

3 ICM, Copenhagen Business School, Frederiksberg, Denmark

\section{Keywords}

Fashion consumption, sustainable fashion, sustainable fashion pioneers, anti-consumption, second-hand/DIY consumption

\section{Correspondence}

Wencke Gwozdz, Department of Communication and Management Copenhagen Business School, Porcelænshaven 18B (1.118), DK200o, Frederiksberg Denmark.

E-mail: wg.ikl@cbs.dk 


\title{
Exit from the High Street An exploratory study of sustainable fashion consumption pioneers
}

\begin{abstract}
.
In today's fashion system, dominated by business models predicated on continual consumption and globalized production systems that have major environmental and social impacts, the consumption of 'sustainable fashion' takes on an almost paradoxical quality. This paper explores this paradox by focusing on a previously under-researched group of consumers 'sustainable fashion consumption pioneers' who actively engage and shape their own discourse around the notion of sustainable fashion consumption. These pioneers actively create and communicate strategies for sustainable fashion behaviour that can overcome the nebulous and somewhat paradoxical reality that sustainable development in the fashion industry presents. Specifically, we use passive netnography and semi-structured interviews to illuminate the role of motivational and contextual factors that help shape these consumers' definitions of sustainable fashion including such key behaviours as purchasing fewer garments of higher quality, exiting the retail market, purchasing only second-hand fashion goods, and sewing or upgrading their own clothing. Central to much of these behaviors is the notion that personal style, rather than fashion, can bridge the potential disconnect between sustainability and fashion while also facilitating a sense of well-being not found in traditional fashion consumption. As such, our research suggests that for these consumers sustainability is as much about reducing measurable environmental or social impacts as it is about incorporating broader concepts through which to achieve goals beyond the pro-environmental or ethical.
\end{abstract}

Key words

Anti-consumption, second-hand/DIY consumption, fashion consumption, sustainable fashion, sustainable fashion consumption pioneers 


\section{BACKGROUND}

Like many industries competing in today's landscape, the fashion industry is rife with environmental and social negative externalities. Environmental degradation, hazardous chemicals, low wages, violation of workers' rights, and child labour are all issues that plague the fashion industry (Fletcher, 2008). Moreover, the current fashion system itself is characterized by planned obsolescence which arguably has become even more acute with the advent of fast fashion. Fast fashion is a successful and increasingly prevalent business model in which fashion retailers create cheap, throwaway goods at much lower costs their designer counterparts and have multiple seasons instead of the traditional two collections per year (Birtwistle and Moore, 2007). As a result, the rate of fashion obsolence has sped up, presumably to the detriment of long-term sustainability. One promising avenue to resolve the tensions between sustainability and fashion is to learn from a small group of vocal and pro-active consumers who actively attempt to address the potential disconnect presented by sustainable fashion. These consumers are pioneers, on the forefront of a lifestyle choice which they promote through personal blogs, online group memberships and other communication forums. As witnessed through the growing presence of eco fashion weeks in major fashion centers and the UN Global Compact's first industry specific initiative dealing with the fashion industry, these sustainable fashion consumption pioneers may be on the front end of a movement to change fashion consumption.

Examining fashion consumption from a sustainability perspective, therefore, calls for closer examination of the concept, which has been subject to myriad meanings and interpretations (Schaefer and Crane, 2005). The term 'sustainable consumption'first entered international policy and research on Agenda 21, the action plan for sustainable development adopted at the 1992 Rio Earth Summit. Although conceived as a pluralistic concept, at its core were the notions of more efficiently produced goods and a 'green' and 'ethical'consumer who in making consumption decisions serves as the driving force of a market transformation that incorporates both social and environmental concerns (Seyfang, 2011). Later discourses explanded this basic framework to include consistency (McDonough and Braungart, 2002), the production of goods 
with materials that can be fully re-used, composted, or recycled; and sufficiency (Princen, 2005), 'living better with less'. Anti- or reduced consumption has also been studied within such movements as voluntary simplicity, asceticism, constrained consumption, downshifting, and non-materialism (Cherrier, 2009; Black and Cherrier, 2010). Closely related to anticonsumption is consumption rejection, which are consumer movements aimed at enacting change in the marketplace through boycotts or protest. This complexity of terminology is not lost on consumers, many of whom have adopted their own definitions of conscious consumer behaviour amidst the confusion and contradictions (Moisander, 2007).

Also far from straightforward is the related concept 'fashion consumption'. Beyond clothing that serves the basic needs of coverage and modesty, fashion embodies symbolic meanings and shares some level of mutual social understanding. In similar vein, Solomon and Rabolt (2004) suggest that fashion is 'a style of dress that is accepted by a large group of people at any given time' (p. 6). It is a form of non-verbal communication which reflects symbolic and social consumption with an aim to manage identity (Ostberg, 2012). Fashion has the power to promote an individual's self-image which is composed of expression of uniqueness and social conformity (Marsh et al., 2010). Murray (2002, p. 438) suggests that fashion can mediate the tension between personalized and commodified experiences. Thompson \& Haytko (1997) suggest that despite the presumed dominant logic of the fashion system, consumers often create their own meanings which Marion and Nairn (2011) describe as fashion "bricoleurs” who work within the constraints of the fashion system to create their own individualized looks to convey their life narratives. In this vein, some authors distinguish between the characterization of "style" and "fashion" suggesting that fashion is characterized by external dictation and frivolous consumption whereas personal style is unique to the individual and a timeless expression (Mikkonen et al., 2014).

For the purposes of this paper, we consider fashion garments to be symbolic resources that exist in a state of transience, a notion profoundly antithetical to the longevity implied by sustainability (Black, 2008). This makes it particularely difficult to define what constitutes “sustainable fashion”. The sustainable fashion lexicon includes myriad terms - including 
'environmental', ‘ecological', 'green', ‘sustainable', ‘ethical', 'recycled', and 'organic'- that are often used interchangeably, thereby confusing researchers and consumers alike (Thomas, 2008).

In the light of the many environmental and social factors contributing to the (non)sustainability of the production and consumption of garments, the lack of theoretical and conceptual work in the field as well as only scarce empirical evidence about influencing factors and their ambivalences, it is probably not surprising that the concept of sustainable fashion consumption is a highly contested concept, if not an oxymoron. Indeed, very little is known about the sustainable consumption patterns of fashion consumers or how consumers conceptualize the meaning of sustainable fashion.

The primary aim of our exploratory study is to learn from an under-researched yet vocal and active extreme consumer group of 'sustainable fashion consumption pioneers' who are publicly engaging in strategies they conceive as "sustainable fashion consumption.” Our research pays particular attention to (i) their conceptualizations of sustainable fashion consumption, (ii) their fashion consumption - which has yet to be a focus of sustainable consumption research and (iii) their strategies for bridging the disconnect between sustainability and fashion consumption. For the latter, we focus, in particular, on contextual and motivational factors, both promising insights into the barriers and drivers to engage into sustainable fashion consumption. Because of the explorative nature of the study, we employ passive netnography combined with semistructured interviews. This study contributes to the sustainable consumption discourse by gaining understanding of a vocal group of consumers who define themselves as sustainable fashion consumers, i.e., how they conceptualize sustainable fashion consumption, what kind of alternative behavioural strategies they choose and what motivates, facilitates and hinders their desired sustainable behaviours. The identified behavioural strategies as well as the contextual factors and motivations behind could be transferrable to better understand and promote sustainable fashion consumption among less sustainable fashion consumers. We expect such an analysis to highlight potential starting points for the promotion of more sustainable fashion systems. 


\section{LITERATURE REVIEW}

\section{(Un)Sustainable fashion consumption behaviour}

Prior studies suggest that only a very small group of consumers actually take sustainability concerns into account when shopping for clothes (Butler and Francis, 1997; Connell, 2011), an observation variously attributed to cost considerations, interest, availability and (lack of) knowledge (Butler and Francis, 1997). In addition to this often observed attitude-behaviour gap between consumer intentions and actions, some research also identifies a mismatch between behaviours that consumers perceive as sustainable and those scientific studies suggest to be sustainable (Connell, 2011). This finding reflects the confusing and conflicting accounts that complicate sustainable consumption decisions (Kozinets, 2011).

Even the reports of those who claim to engage in sustainable fashion consumption can be interpreted in many different ways. Connell (2011), for example, suggests that some consumers attempt sustainability by purchasing items that can be worn for a long period of time. Fibre content is also a frequent consideration for those looking to behave pro-environmentally, with natural fibre content or recycled fibres being preferred over synthetic fibres. Yet lifecycle assessments in fact suggest that, depending on the resource and impact being measured, natural fibres like wool and traditional cotton frequently have more environmental impacts than synthetic alternatives (Fletcher, 2008).

There is also evidence that consumers try to extend their clothing's aesthetic and physical durability in the name of sustainability by repairing or re-fashioning (Connell, 2011). They may also limit washing/drying behaviours, although sometimes for clothing maintenance or financial savings rather than pro-environmental concerns (Laitala et al., 2011). Disposal is generally divided into four possible behaviours: throwing items away, giving or selling them to another person or second-hand shop, donating clothing to charity or lending it to another person (HaBrookshire and Hodges, 2009).

\section{The consumption context}

The consumption context refers to internal and external factors to the consumer which influence consumer behaviour. Internal factors specific to individual consumers like resources 
and task specific knowledge are often cited as a pre-requisite for pro-environmental behaviour (Thøgersen, 2010) and many social campaigns have sought to induce behavioural change by creating consumer awareness. This is not clear cut however, as consumer knowledge has also been linked to information overload in which excessive information - often of a conflicting nature - can cause consumers to feel overwhelmed and unable to act (Kozinets, 2010).

Referring to this knowledge conundrum as our 'inability to know', Beck (1998) proposes that the greater amount of information available today prompts tension and confusion over the proper action to take.

Similiarily the presence or absence of financial and temporal resources can also impact sustainable behaviour, though not always in a clear cut manner. Often sustainable consumption, particularely the purchasing of green or sustainable goods, is linked to consumers with increased economic resources (Alberini et al., 2005). Some forms of sustainable behaviour however, including voluntary simplicity (Black and Cherrier, 2010), consumption rejection (Sanne, 2002) and simply more planful shopping behaviour (Carrigan and de Pelsmacker, 2009) have been shown to be viable means for saving money. These behaviours, however, can also draw heavily on consumers' temporal resources; that is, sustainable consumption is often time rather than money intensive. Starr (2009) therefore distinguishes between 'buying' and 'behaving' sustainably, suggesting an inherent trade-off between access to temporal and to financial resources.

External factors that have been cited for influencing sustainable consumption behavior include a limited choice of pro-environmental products, structural conditions that facilitate or impede sustainable behavior and deeply embedded social and cultural norms that tacitly dictate behaviour (Thøgersen, 2010). Many studies (Birtwistle and Moore, 2007; Ha-Brookshire and Hodges, 2009) conclude that regardless of environmental concern, consumers are more likely to donate, recycle or hand down clothing if the infrastructure for doing so is widely available and easy to use. Particular attention has been given to the 'consumer culture' that is dominant in richer parts of the world (Lury, 1996) which profoundly impact consumption: Products are purchased not simply to satisfy individual needs but to satisfy a host of other objectives including identity creation, symbolic self-completion, distinction and adaption (Jackson, 2005). 
This cultural meaning provided by goods is thought to be continually in transition (McCracken, 1986). Such transience can in turn fuel an on-going need for consumption to maintain a desired social position. The Western fashion system appears to epitomize this, characterized by rapid change, a profusion of styles, cheap goods and thus mass consumption of goods (Thompson and Haytko, 1997). Fashion critics therefore suggest that 'fashion immerses consumers' selfperceptions in cultural meanings and social ideals that foster depthless, materialistic outlooks and a perpetual state of dissatisfaction over one’s current lifestyle and physical appearance' (Faurschou, 1987, p. 82). This critique is not limited to the symbolic nature of the fashion system however, as Soper (2007), for instance, maintains that 'capitalist lifestyle ideals permeate all aspects of consumer culture' (p. 209), while Sanne (2002) argues that both the state and self-interested businesses habitually create conducive conditions for increased consumption.

\section{Consumer motivations}

Much discourse has sought to understand why consumers are motivated to consume sustainably. Whereas early research has viewed sustainable consumption being driven by altruistically motivated consumers with high concern for environmental and social issues (Stern et al., 1995), more recent work hints at sustainable consumption's self-interested facets (Black and Cherrier, 2010). For example, sustainable consumption has been closely linked to the formation and reinforcement of the self, signalling uniqueness, distinction and group cohesion and bridge the actual and ideal selves (Connolly and Prothero, 2008). Cherrier (2009) particularly describes creative consumers who reject commercialization as part of both their identity construction and a desire to find meaning in their consumption practices. Cherrier argues that beyond helping consumers construct unique identities, sustainable consumption gives them a sense of empowerment through the avoidance of status goods and competitive social hierarchies.

Research on consumer movements such as voluntary simplicity, asceticism and nonmaterialism further identify a link between reduced consumption and subjective happiness and well-being (Cherrier, 2009; Fournier, 1998). Soper (2007) offers the 'alternative hedonist' perspective that many consumers who find displeasure in the by-products of affluence have simply reconstituted the nature of 'the good life'. Alternative consumption behaviours, Soper argues, provide not only moral rewards but sensual pleasures. A sensory focus also underpins 
the argument that sustainable consumerism can be motivated by a desire for 'enchantment' or the experiential outcome of selecting alternative consumption rituals such as eating locally ethically produced food (Thompson and Coskuner-Balli, 2007). Szmigin and Carrigan (2005) conceptualize this desire as an ethical hedonism in which the action produces pleasure and prevents pain. Such ethical consumption, they claim, can create an aesthetic experience by providing an antithesis to mass produced goods, while the 'feeling' engendered by the creation of socially and environmentally just goods can create a halo of aesthetic beauty.

Research also indicates that sustainable consumption can be motivated by negative emotions such as mistrust and scepticism.Cherrier (2009), for instance, points to future uncertainty and 'living in an uncontrollable world' as powerful discourses motivating anticonsumption consumer movements. Studies also show that because of distrust, consumers may form resistance to large corporate brands (Kozinets and Handelman, 2004; Luedicke et al., 2010). According to Carrigan and Attalla (2001), much of this resistance comes from large companies' inherent opacity and lack of authenticity, which leads to consumer scepticism of their ethical motives (Thompson and Arsel, 2004). Holt (2002) concludes that consumers resist large corporate brands in an effort to pursue individual freedom from the perceived control of the market. Consumers can, for example, be resistant to the homogenization that large brands enact on local communities, preferring the seemingly authentic nature of smaller local retailers (Thompson and Arsel, 2004). They may also seek authenticity as a response to the fragmentation and alienation elicited by postmodern cultural forces like globalization (Arnould and Price, 2000; Firat and Venketash, 1995; Holt, 2002). Often these consumer attempts to escape the market in search of authenticity and uniqueness are thwarted however, when the alternative modes of consumption become commercialized by larger interests (Murray, 2002). This can leave the consumer on a perpetual journey to find and "emancipated space" from the mainstream market (Murray, 2002, p. 439)

\section{METHODOLOGY}

Because research on sustainable fashion consumption pioneers is currently so limited, this study adopts an interpretive methodological approach (Lincoln and Guba, 1985) that is 
inductive and exploratory. The primary aim is to analyze an as yet under-researched extreme consumer group to uncover their conceptualizations of sustainable fashion consumption and identify their strategies for bridging the disconnect between fashion consumption and sustainability. The most apt site for exploring how consumers negotiate sustainable fashion consumption proved to be the online context, not least because it allowed an expansive search for participants free of geographic limitations and the active monitoring of on-going and relevant discourse in this niche consumption area. More important, developments in online digital media have radically changed how consumers engage in their daily lives, blurring the line between 'real' and virtual interactions (Kozinets, 2010). Online spaces have become crucial for understanding contemporary consumption (Beer and Burrows, 2007). In regards to sustainable consumption specifically, social media and other participatory web forms are being studied as places in which consumers can come together, find empowerment, form marketplace resistance and find an innovation context for co-creating new visions (Kozinets et al., 2011). Due to the limited number of online communities (on sustainable fashion consumption) rich in active dialogues and participation, we broadened the search to other online presences, including personal blogs, forums, online magazines, online stores and social networks (LinkedIn and Twitter). Because these online presences followed a one-way communication (i.e. without interactive dialogue), we adopted a passive netnographic approach comprising two components: (i) an observational netnography analysis of online content and (ii) offline interviews that added depth to our understanding (Kozinets, 2010).

\section{Data collection and sample}

The fieldwork was carried out between July and December 2011. Our sampling process was iterative, employing on-going screening of potential participants which evolved throughout the research as we gained insight from the field. Participants were initially recruited via theoretical sampling (Glaser and Strauss, 1967) in which we searched Internet groups, online forums, personal blogs, online stores and websites using a wide array of terminology in an attempt to uncover how the sustainable fashion lexicon was represented in the field. We began by posting on the Ethical Fashion Forum and on such social networks as Twitter and LinkedIn under such 
groups as ‘green my style’, ‘slow fashion', ‘LOHAS’, ‘conscious fashion’ and ‘eco fashion network'. These initial observations led to early interviews with participants actively engaged with relevant sites. As the research progressed, we subsequently amended our search terms based on interview feedback; for example, expanding the search to do-it-yourself (DIY) blogs, anti-shopping competitions, second-hand blogs, and other forms of sustainable fashion consumption. All participants gave permission to use interview and blog material.

Our search suggested that "sustainable fashion” and related terminology was relatively limited in both consumer engagement and relevant online activity which helped inform our final sample of 10 participants. Thus while small in overall size, this sample is relative to the overall niche participation in sustainable fashion consumption. In total, we reached out to 30 potential participants who we selected based on online activity (i.e. those who kept regularly update their online content were contacted), selecting a variety of participants from different sites and geographic regions located in developed western countries. The global reach of our sample allowed us more breadth in our sample given the limited consumer engagement in this niche area of consumption.

To ensure a sample that negotiated the potential fashion-sustainability tension, this screening process addressed both sustainable fashion behaviours and fashion involvement. With regards to fashion involvement, we screened potential interviewees to determine whether they had an interest in clothing as a form of self-expression rather than as a means to fulfill utilitarian needs. With regards to sustainable behaviour, the research's inductive nature facilitated the emergence of themes not explored in earlier studies by making room for informant-defined notions of sustainability not yet considered. Thus, we screened participants to ensure they were engaging in behaviors they deemed sustainable rather than only considering traditional industry or academic notions of sustainability.

Once identified as meeting the criteria, participants engaged in hour-long semi-structured interviews, 8 conducted by phone because of geographic limitations, 1 in person, and 1 by email at the informant's request because of a language barrier. These semi-structured interviews were guided primarily by the participants, although to ensure identification of the potential disconnects between academic, industry and consumer notions of sustainability, respondents not 
freely volunteering descriptions of their behaviours throughout the consumption phases were specifically asked for such information. The data from the recorded and transcribed interviews were supplemented by a concurrent observational netnography (Kozinets, 2010) in which we analyzed participants’ online presences by pasting excerpts from their online content into word documents and identified prevalent sustainable fashion consumption themes. After 8 interviews, we reached a theoretical saturation point at which the data elicited no longer felt new (Glaser and Strauss, 1967). Nevertheless, we carried on with the two additional interviews to ensure that we had indeed reached saturation and then continued monitoring our selected sample's online content.

The on-going data collection soon revealed that our participants, whose characteristics are summarized in Table 1, were driven by the overarching goal of changing the system through pro-active and innovative acts of sustainability. Such a pro-active stance was evidenced by their active engagement in promoting sustainable fashion as a way to achieve stylistic expression without the trappings of "fashion."

Table 1 about here

\section{Data analysis}

Given that the research was exploratory the approach was grounded (Bryman and Bell, 2003) analysis of the interview transcripts and web content was done (Arnold and Fischer, 1994) iteratively throughout the data collection, with each individual's interview and web content being read and analysed for thematic findings free of any theoretical frame. Initial interviews and observations helped shape further interviews as we began to uncover prevelant themes while still remaining open to emergent and participant guided findings. Participants’ online content was monitored retroactively (i.e. past blog posts were pulled for analysis) and then followed throughout the whole fieldwork period as the participants continued to actively 
post content. Manual coding was done in an ongoing manner, first at an individual participant level and then we as we began to see emerging themes we re-analzyed the data to pinpoint the most encompassing themes from all of the interviews and web content. The most substantive content was then aggregated into the aims of the study, namely: the conceptualization of sustainable fashion consumption by the sustainable fashion consumption pioneers, their reported behavioural strategies as well as how they bridge the tensions between sustainability and fashion consumption by looking into the contextual and motivational factors that appear to contribute to their understanding and engagement in sustainable fashion consumption.

\section{RESULTS}

We outline our main thematic findings according to the aims to the study, whose delimitations are used to identify the consumption contexts and motivations of the sustainable fashion consumption pioneers. Table 2 summarizes the motivational and contextual themes identified.

Table 2 about here

\section{Motivation}

The motivational themes identified represent the factors that participants suggested compelled them to engage in sustainable consumption. The primary themes, highlighted below, include consumption as sustainability's antithesis, sustainability as a facilitator of style, and sustainable fashion as a source of pleasure and well-being.

Consumption as sustainability's antithesis. The participants' conceptualizations of sustainability are strongly related to the belief that 'consumption is the antithesis of sustainability', a sentiment echoed in studies of other consumer movements, including voluntary simplicity, downshifting and non-materialism (Cherrier, 2009; Fournier, 1998). Particularly 
vilified as an antithesis to sustainability is the fast fashion model, to which Noel objected on the following grounds:

[The fast fashion model] is a contradiction because fashion is about speed and it's about consuming and it's about change. Sustainability is about slow[ness], it's about ... being careful with your raw materials and about being stable about the future.

Hence, as suggested by Thomas (2008), the sustainable fashion consumption pioneers appear sceptical of the sustainability efforts of major fashion retailers. Indeed, several participants echoed Faurschou 's (1987) claim that fashion producers and retailers, although they offer single sustainable options, still rely on hyper-consumption and cheap prices to meet their business demands. Noel, for example, referring to H\&Ms recent decision to offer organic cotton, argued that

... their whole business model is based on selling a lot of fast fashion cheaply, and I think there is no way they can be sustainable. I mean, their Conscious Collection is what... 1 per cent of what they make in a year? And my feeling is that they only do this so they can say, 'Hey look, we're sustainable'.

Most participants in fact appear adamant that sustainability is a holistic endeavour, one requiring both societal and environmental considerations and thus not achievable through a 'green product line', which Sandra associated with a 'flavour of greenwashing'.

Also implicit in this attitude is the notion that, if a company's purpose for engaging in sustainability is linked to profit or sales growth, its sustainability efforts are untrustworthy. For instance, the participants frequently invoked the word 'authentic', implying that sustainability requires genuine engagement, something belied by profit motives (see e.g. Holt, 2002; Thompson and Arsel, 2004). This notion of authentic engagement is built on intangible associations, with an inherent scepticism of 'self-interested' large multinationals and an intuitive sense of trust in small or local producers, who are perceived as 'truly believing in what they are doing' and 'passionate about their cause'.

Sustainability as a facilitator of style. As in other studies on the expression of sustainable consumption, our participants' engagement with sustainable consumption has engendered deeper notions of self (see Connolly and Prothero, 2008) and helped to solidify values and aspirations like individuality and freedom from the fashion system and mass culture (see 
Cherrier, 2009). Our participants conceptualize this sentiment by invoking the word 'style' and clearly distinguishing between 'style' and 'fashion'. This latter they imbue with such connotations as 'dictation from above', 'short term' and 'trendy', all symbolizing a lack of individuality and aesthetic conformity - in line with how Mikkonen et al. (2014) suggest "style" has characterized by mainstream media outlets. The participants also frequently differentiate between their own behaviours and those of the 'follower' mainstream. For example, when asked whether she saw herself as fashionable, Mae Ann immediately protested 'No, no, I would not say that!” and instead described her personal style and self-perception as that of an individual with a unique, non-dictated way of wearing garments that is closer to art than material consumption. Style, the participants argue, requires two traits that they value greatly: creativity and self-awareness. Hence for them, freedom from fashion is a more sustainable way of consuming because it negates the need for the perpetual 'seasonal' fashion consumption (see also Thompson and Haytko, 1997). As Noel explained it, 'I no longer get bored, which is what I want to promote. Fashion is about creativity and not about adding new stuff'. Our findings thus echo Marion and Nairn’s (2011) and Thompson and Haytko’s (1997) findings that consumers work creatively within the constraints of the fashion system to re-appropriate meanings suited to their life goals and narratives.

Sustainable fashion as a source of pleasure and well-being. As reported in other research, sustainable consumption provides our respondents with an apparent sense of personal growth, well-being and experiential pleasure (Szmigin and Carrigan, 2005), which Thompson and Coskuner-Balli (2007) term 'enchantment'. For example, when asked the number one reason that others should follow in her path of sustainable fashion consumption, Sandra replied simply, 'For well-being. It is a better way to live'. Because sustainable fashion consumption was a relatively new endeavour for many of them, our participants found it easy to reflect on the changes it has wrought. Several respondents described how the pleasure once associated with the consumption of fashion goods has been replaced by larger goals of self-fulfilment and selfimprovement. For instance, they frequently associated such sentiments with the word 'comfort,' not in the corporeal sense but rather in terms of the freedom and confidence they had found in themselves. Some did report experiencing more comfort in their body image as a result of 
removing themselves from mainstream fashion. Like other creative consumers (see e.g. Cherrier, 2009), these sustainable fashion consumption pioneers also described a sense of comfort and relief at being free from previously felt competitive pressures to consume. As Chloe put it,

[i]n the past, when I was earning a really low salary, I always kind of felt entitled to new things. And I always felt a bit perturbed that I couldn’t afford things my friends could. Now I care very little. I don’t really care what my friends can afford compared to me. It has put a lot of things into perspective for me.

\section{Consumption context}

Many of the motivational themes described above can be closely linked to the consumption contexts in which they were formed, with many participants forging their own definitions of sustainability within their personal contextual frameworks. Besides shaping consumer motivations, contextual factors can play a strong role in facilitating or hindering whether motivations become behaviour realities (Thøgersen, 2010). In this research, the most salient internal contextual themes cited were knowledge and re-conceptualization of resources. The most often cited external contextual factors were distant opaque markets and the societal pressure to consume.

The knowledge conundrum. Although insufficient in itself, knowledge, particularly taskspecific knowledge, is generally seen as a prerequisite for sustainable behaviour (Thøgersen, 2010), and our participants did in fact demonstrate a vast amount of knowledge about sustainability issues in the fashion industry. Yet this same knowledge presented them with a source of confusion and complexity for which sustainability offers no clear answer, a conundrum Beck (1998) labels the 'inability to know’. Participants often complained, for instance, of trade-offs inherent in the many decisions related to fabric choice, labour standards and other factors influencing sustainability. This lack of clarity, coupled with their own distrust, makes them sceptical of traditional sustainable offerings. In addition, their conceptualizations of sustainable fashion, rather than being shaped by sustainability facts or figures, are most often influenced by direct experience working in the fashion industry. For example, several 
participants explained how their deep knowledge of fashion production has helped them understand the value and work that goes into creating garments, something they feel other consumers may not understand. In Noel's words,

I understand that if you wear a cotton dress, people have had to put in a lot of effort before the cotton was there. I was working for a web shop, and we sold garments, and I told the people I was working with that everything we sold was made by real people. They just thought a t-shirt comes from a factory somewhere, and they have no idea that there is a human who must push it through the machine.

Not only were such sentiments echoed by other participants, but this realization appears to shape the fashion consumption pioneers' belief that goods are not valued at their 'true' market prices and that 'cheap’ cannot be truly sustainable. They also expressed scepticism about organic or recycled textiles offered in fast fashion settings, suggesting that despite their proenviromental content they were antithetical to sustainability given their intended short term use. It is these sustainability inferences - rather than scientifically based sustainability facts or figures - that tend to drive their sustainable behaviours.

Re-conceptualization of resources. Although in general, research has treated temporal and financial resources as a fixed variable and linked deficiencies to unsustainable consumption patterns (Starr, 2009), this study finds these resources to be somewhat subjective and related to consumers’ value priorities, interests and, more important, their conceptualizations of sustainability. Hence, even though all the sustainable fashion consumption pioneers reported busy lifestyles, none suggested having too little time to spend on sustainability efforts. In fact, some commented that their decision to shop less actually afforded them more time for meaningful activities. Nevertheless, many of the behaviours described did suggest that the actual temporal effort required by their modes of sustainable fashion consumption is far greater than they perceive it to be. Yet their high levels of interest and involvement and the pleasure derived from activities like sewing their own clothing or second-hand shopping reduces the temporal barrier noted by other consumers, suggesting that the time resource is less of an issue in intrinsically motivated sustainable activities.

The sustainable fashion consumption pioneers also seem able to overcome the limited financial means identified as an inhibitor of sustainable consumption behaviour. As reported in 
other research comparing sustainability-based lifestyles (Carrigan and de Pelsmacker, 2009) with the purchasing of sustainable goods (Starr, 2009), those with insufficient resources find alternative routes (e.g. buying second-hand or making their own clothes) that are actually less expensive than shopping in traditional retail settings. Reducing consumption altogether also implies financial savings. Nevertheless, there does appear to be a trade-off between temporal and financial resources: sustainable consumption activities that require more time may cost less money and vice versa (Starr, 2009).

Distant opaque markets. When asked about barriers to making sustainable fashion consumption an achievable reality, our participants referred especially to distance, speed and opacity in today’s global production system (see Arnould and Price, 2000; Beck, 1998). Most particularly, they lamented the impossibility of knowing the true provenance of a textile or which labourers produced it, a problem to a large extent linked to modernization and globalization. Marie, for example, was sure that

one hundred or $99 \%$ of what people wear they cannot trace. They can barely remember where they purchased it, much less whose hands created it. I think dislocation from the source is problematic. It lets things like polluting the water table in a community in Asia or hiring child labourers to produce a product in a foreign country be OK because that disconnect is there and consumers cannot see it.

As this comment suggests, our participants suspect that consumers have a hard time caring about cannot see or feel, which they largely blame on modern global production systems. They contrasted this situation with reverent descriptions of a past in which consumption was slower and localized and consumers could come face to face with producers (cf. Thompson and Arsel, 2004). At the same time, their conceptualizations of sustainability hinge greatly on perceived transparency, something they deem nearly impossible when dealing with large retailers (cf. Carrigan and Attalla, 2001). This linkage in turn helps shape their belief that 'small and local' carries an air of sustainability, while large and profit-driven equals untrustworthy and unsustainable.

Societal pressure to consume. Building on their criticism of the fashion system, participants identified the market system itself as a barrier to sustainable consumption. Specifically, reminiscent of the viewpoint that it is a citizens's duty to consume (Sanne, 2002), they claimed 
that for most citizens, consumption is simply a fact of life, with governments and companies equally complicit in its fuelling and promotion. The systemic problem, they argued, stems from the never ending need for profit, which leads to a search for low-cost labour and cheaper materials and an increased use of resources to satisfy growing sales. This structural reality directly contradicts their belief that the only way to consume sustainably is to consume less. Maura refers to this feeling of entrapment on her blog:

I know I'm not the only one who feels like the system is broken. But do we really have no choice but to continue to operate within the system we hate? What is the alternative? Falling off the grid and joining a commune?

For our participants, the fashion system represents the apex of the consumptionsustainability paradox. It also perpetuates the need to consume through its grip on consumers and their desire to fit in with others (Faurschou, 1987). Noel, for example, recounted her own past behaviour:

I was studying fashion, and I would be really influenced and inspired by the people around me. I would get new impressions every day, and I would want to adapt.

Our participants thus argued that, being predicated on profit models that demand seasonal creation and destruction, the fashion system simply cannot be reconciled with sustainable product offerings. As Maura commented,

[i]t was one thing to have two fashion seasons a year, but now we have six or seven. It is exhausting. The way the fashion industry is structured, the environment is inherently unsustainable, and it is going to take a really big paradigm shift for us to be able to shop at all.

\section{Behavioural strategies}

Although the behaviours reported by the sustainable fashion consumption pioneers are potentially more aspirational than realistic, the descriptions themselves offer valuable lessons. In particular, they illuminate how these consumers navigate a relatively undeveloped consumption domain rife with potential paradox. The participants favour the term 'sustainable fashion' (cf. Thomas, 2008), believing the two words incompatible and likely to create mistrust and confusion. These observations suggest that sustainable fashion consumption pioneers often construct the behaviours they engage in and limit their interaction with the mainstream high 
street market by selecting innovative sustainable behaviours that have little to do with current industry definitions of such sustainable offerings as recycled textiles, organic materials or ecolabels. Rather, as Moisander (2007) suggests, our participants create their own definitions of sustainable fashion consumption amidst the confusion and contradictions.

In addition, despite the expected overlap in many participants' behaviours, we were able to identify two slightly divergent groups, those who 'consume less/consume better' (CLCB) and those who practice 'second-hand/DIY' (2DIY). The CLCB group described their sustainable consumption behaviour as purchasing fewer but higher quality goods from artisanal or small producers rather than from mass retailers on the high street. Their consumption principles are thus similar to those professed in the voluntary simplifier and slow fashion consumer movements (e.g. Cherrier, 2009; Fournier, 1998). The 2DIY group, in contrast, reported exclusively purchasing second-hand garments or making their own garments, behaviours also reported in Connell's (2011) research on eco-conscious fashion consumption behaviour and Portwood-Stacer's (2012) study of anti-consumption activists.

Most important to the CLCB group reported to 'consuming less' and buying from trustworthy retailers, which they judge a form of sustainable consumption. Several reported appeasing their desire to consume by 'shopping in their own closets', by re-discovering and reimagining clothing already owned. When they do shop, they use other information sources (e.g. place of origin) as sustainability indicators. Elena, for instance, first searches retailers’ websites for content on the company's sustainability initiatives and then uses in-store information particularly tags and labels - to determine where the item was made: 'If it says Bangladesh or Cambodia, that is not a good sign'. Price also serves as a sustainability indicator, with very low prices immediately discounted as unsustainable. As regards fabric content, although the issue was mentioned, in line with the problem inherent in identifying the most sustainable fabric choices (Fletcher, 2008), their feelings on what constitutes 'more sustainable' behaviour were mixed, possibly because of the knowledge condundrum.

The 2DIY group, in contrast, expends less effort on determining clothing's sustainable features and avoids the associated tedium and conflict by exiting the fashion system, which seemingly leads to less guilt over consumption frequency. Instead, they spend much of their 
time rummaging through second-hand bins or sewing and designing their own clothing. Their exit from the system seemed to allow for less guilt over their consumption frequency. Chloe, for example, reported sewing her own clothing exclusively but without purchasing any fabric in a year because it has 'become commercialized'. Rather, she makes herself new garments weekly out of used scraps. Likewise, Sharon reported that since beginning to purchase used, she has felt less constricted by the notion of less and no longer feels the guilt associated with her high street purchases.

Interestingly, although many recent lifecycle assessments have identified garment care washing, tumble drying and dry cleaning - as a key contributor to fashion's total environmental footprint (Fletcher, 2008), this issue was conspiculously absent from most interviews. Rather, the interviewees conceptualized ‘sustainable fashion' as a way of purchasing clothing - not caring for it. When questioned specifically about laundering clothes, they expressed varying degrees of concern, with several limiting the numbers of washes to prolong the life of their clothing but only two reporting the use of a tumble dryer. These actions hint at sustainable behaviours other than those witnessed in the mainstream.

Additionally, in contrast to recent research evidence that Western consumers typically throw away an abundance of clothing items (Birtwistle and Moore, 2007), our sustainable fashion consumption pioneers reported ‘zero binning' of their used clothing. The most commonly cited means for removing clothing from the wardrobe at the end of use were giving clothing to charity shops or friends or organized clothing swaps.

\section{DISCUSSION}

For researchers, the fashion industry and consumers alike, the term 'sustainable fashion' remains ill-defined, confusing and paradoxical. The 10 participants interviewed for this study, however, appear to have overcome the inherent tension and complexity by forging their own conception, a fuzzy notion of sustainable fashion that is compelled and shaped by motivational and contextual factors rather than distinct industry notions of sustainability. For them, as for other ethically minded consumers (Black and Cherrier, 2010; Cherrier, 2009; Kozinets and Handelman, 2004; Thompson and Arsel, 2004), sustainability is as much about reducing 
measurable environmental or social impact as it is about incorporating broader concepts through which to achieve goals beyond the pro-environmental or ethical, including freedom, uniqueness, resistance, authenticity, trust and well-being. As such their reported behaviour works outside the confines of the high street fashion system, with them appropriating their own notions of sustainable fashion based on these deeper goals.

Many of the respondents' definitions seem clearly driven by the perceived disconnect between 'sustainability' and 'fashion', the first defined in terms of 'endurance', 'the long term', and 'conscious decisions'; the second unanimously vilified as conveying 'waste', 'transience', and 'dictation'. The participants apparently mediate the tension between these two concepts by invoking the notion of personal style as a source of sustainability, a notion that carries deeper meanings of uniqueness and freedom. Consistent with earlier findings on consumer motivations to engage in sustainability (Black and Cherrier, 2010; Connolly and Prothero, 2008), personal style serves as both a strategy for and a desired outcome of sustainable consumption, allowing them to bypass the pitfalls of modern consumption while achieving greater goals of nonconformity and distinction.

For the sustainable fashion consumption pioneers, the same structural barriers that impede sustainable consumption have become part of the sustainability definition, so that their acts of sustainability embody a form of resistance to seemingly insurpassable systemic barriers. All participants posited, for example, that reduced consumption is the only true way to achieve sustainability but a near impossibility in a profit-fuelled context. They have thus modified their sustainable fashion consumption behaviours to resist the system, abandoning traditional means of fashion consumption in favour of alternative options like second-hand shopping or small local retailers. Hence, whereas other research reports similar acts of consumption avoidance to achieve a greater societal goal (e.g. Kozinets and Handelman, 2004), in our study, the notion of sustainability reflects a more subtle and less confrontational means of staging resistance. This brings and inherent tension in the mass adoption of sustainable fashion and the current motivations to engage in the practices. Once larger market logics engage in the discourse, as Murray (2002) suggests, there is the distinct possibility that sustainable fashion consumption pioneers will no longer feel the freedom the market this mode of consumption allowed them. 
Trust and authenticity are also inextricably linked to our participants’ notion of sustainability: the ideology that a company should engage in sustainability for itself rather than for profit or other self-interested motives was implicit in most interviews. As a result, the participants view the sustainability efforts of large high street retailers as opportunistic but attribute a halo of legitimacy to small and local retailers (see also Holt, 2002). These perceptions, however, appear to have less to do with environmental impact or statistics than with intuitive emotional associations of sustainability. Hence, our respondents, seeing sustainability as less of a measure and more of a holistic path, discount many retailer recycling schemes or efforts to offer organic or recycled textiles as 'not enough' or 'questionable'

Yet interestingly, despite this disregard for companies who engage in self-interested sustainable actions, the participants' own sustainable behaviour is not necessarily sacrificial or altruistic. Rather, they find pleasure, joy and well-being in their sustainable consumption activities (see also Smizgin and Carrigan, 2005; Soper, 2007; Thompson and Coskuner-Balli, 2007), which implies a double standard. As a result, they are less concerned with the resources typically implicated in constraining sustainable consumption; for example, time and finances.

\section{STUDY LIMITATIONS AND FUTURE RESEARCH}

Our study is, of course, subject to certain limitations. First, as often occurs with socially desirable behaviour, participant responses can reveal discrepancies between reported and actual behaviour. Their public roles as bloggers, for example, could potentially compel them to report a certain type of behaviour consistent with their public persona, and the nature of the online context and geographic limitations prevents validation of their claims. This research, therefore, should be seen as an expression of how sustainable fashion consumption pioneers perceive sustainable fashion consumption not as an account of sustainable behaviours actually witnessed. Nevertheless, the information is valuable in that it identifies what sustainable fashion consumption pioneers perceive as important when discussing sustainable fashion consumption online.

Second, the methodological approach employed has several limitations.The data encompasses only the self-reported behaviours of a small sample of highly selected consumers 
and thus does not address the motivations and contextual facilitators or barriers reported for other important consumer groups. Yet by investigating such an extreme group with a passive netnographic approach, we have gained valuable knowledge about the creative ways in which sustainable fashion consumption pioneers conceptualize and actually live ‘sustainable fashion’, as well as their primary motivations that guide them. These exploratory findings help provide insight for future research that may engage in larger scale studies or look in depth at other segments of fashion consumers with regards to sustainable behavior.

Third, the aims of the study combined with the data gained through the methodological approach led to themes that sometimes draw on consumer behaviour approaches and other times on consumer culture theory. Thus, we draw on both strands of literature to interprete the findings which truly has some limitation of linking these two approaches. However, the benefits in terms of interpreting the findings and gaining a broader picture of sustainable fashion consumption pioneers' conceptualization, behavioural strategies as well as contextual and motivational factors outweigh these limitations. This study demonstrates the utility of drawing on different strands of consumer research that has the potential to offer additional and alternative insights into sustainable consumption.

\section{CONCLUSIONS}

In particular, our findings raise larger questions about the current state of sustainable fashion. If the underpinnings of fashion - transience, seasonality and change - continue to dominate, it is unlikely that consumers will find consonance with their perceptions of sustainability. At the same time, many aspects associated with the notion of fashion are crucial to the adoption of more sustainable fashion behaviours. Aesthetics, novelty and creativity, for example, were all cited as reasons for engaging in fashion consumption, and rather than abandoning such pleasures, the participants have found new ways to satisfy these needs by invoking personal style. It therefore seems that, as long as industry attempts at sustainability are linked to fabric selection or recycling rather than pleasure and self-expression, limited engagement is likely to persist. That is, as long as sustainability efforts fail to consider the 
unsustainable logic of the fashion system, consumers are unlikely to accept these innovations as viable alternatives.

Overall, therefore, our findings offer a valuable opportunity to re-calibrate and re-position the current discourse on sustainable fashion with particular regards to the disconnect in meanings between 'fashion' and 'sustainability'. By reducing the associations with the transient fashion system and instead invoking the participant notions of style, the seeming contradiction perceived by many consumers can be mitigated. Our research suggests that the notion of style engenders similar sentiments to those captured by the ethical food movement (Thompson and Coskuner Balli, 2007), which emphasizes the 'good choice' as the pleasureable one. This recalibration may be particularly important if sustainable fashion is to become less of a niche phenomenon and more widely adopted in the mainstream. Our findings also suggest that The emotional associations of trust and authenticity rank as more sustainable than impact measures or eco labels. Such valuation, although it may well be related to the complexity and contradiction inherent in sustainability, can equally be interpreted as a reaction to the perception that many companies or businesses engage in sustainability efforts only for self-interested gain and profit. This self-interest, whether measurably sustainable or not, minimizes the perceived efforts, thereby calling into question the oft-cited 'business case' for sustainability. This doubt is increased by the fact that although the companies themselves extol the virtues of the 'win-win' scenario of increasing profits by increasing sustainability, our participants apparently see the two as likely to diminish one another. Such a perception makes for a complex situation in which it is precarious for any large profit-driven company to communicate sustainability.

One interesting question remains, however: If sustainability efforts by large multinationals are perceived as meaningless and sustainable fashion consumption facilitates the need for freedom and uniqueness, how can the sustainability agenda actually make an impact on fashion? Pragmatically, achieving large-scale change requires mainstream adoption of sustainable fashion consumerism, a change that large multinational companies must help drive. Yet although those interviewed seemed very interested in extending their behaviours to include other consumers, it is worth contemplating whether this commercialization might not reduce the perceived distinction achieved through such consumption. That is, if sustainable fashion 
consumption becomes mainstream, will these consumers still find it appealing? Or will the logic of sustainable fashion fall victim to the same logic as traditional fashion: 'in today, out tomorrow’?

\section{REFERENCES}

Alberini, A., Rosato, P., Longo, A. \& Zanatta, V. (2005) The effects of information on willingnessto pay: A contingent valuation study of S. Erasmo in the lagoon of Venice. In: Environment, Information and Consumer Behavior (ed. by S. Krarup \& C.S. Russell), pp. 215247. Edward Elgar, Cheltenham.

Arnold, S.J. \& Fischer, E. (1994) Hermeneutics and consumer research. Journal of Consumer Research, 21(1), 55-70.

Beck, U. (1998) The Politics of Risk Society. Polity Press, Cambridge.

Beer, D. \& Burrows, R. (2007) Sociology and, of and in Web 2.0: Some initial considerations. Sociological Research Online, 12(5). Available at: http://www.socresonline.org.uk/12/5/17.html (accessed 18 March 2014).

Birtwistle, G. \& Moore, C. (2007) Fashion clothing - where does it all end up? International Journal of Retail \& Distribution Management, 35(3), 210-216.

Black, S. (2008) Eco-Chic the Fashion Paradox. Black Dog Publishing, London.

Black, I.R. \& Cherrier, H. (2010) Anti-consumption as part of living a sustainable lifestyle: Daily practices, contextual motivations and subjective values. Journal of Consumer Behaviour, 9(6), 437-453.

Bourdieu, P. (1986). The forms of capital. In: Handbook of Theory and Research for the Sociology of Education (ed. by J.G. Richardson), pp. 241-258. Greenwood, New York.

Brundtland, G.H. \& the World Commission on Environment and Development (1987) Our Common Future. Oxford University Press, Oxford.

Bryman, A., \& Bell, E. (2003) Business research methods. Oxford University Press, Oxford, UK.

Butler, S.M. \& Francis, S. (1997) The effects of environmental attitudes on apparel purchasing behavior. Clothing and Textiles Research Journal, 15(2), 76-85.

Carrigan M and Attalla A (2001) The myth of the ethical consumer - do ethics matter in purchase behaviour? Journal of Consumer Marketing 18(7): 560-578.

Carrigan, M. \& De Pelsmacker, P. (2009) Will ethical consumers sustain their values in the global credit crunch? International Marketing Review, 26(6), 674-687.

Cherrier, H. (2009) Anti-consumption discourses and consumer-resistant identities. Journal of Business Research, 62(2), 181-190.

Connell, K.Y.H. (2011) Exploring consumers' perceptions of eco-conscious apparel acquisition behaviors. Social Responsibility Journal, 7(1), 61-73. 
Connolly, J. \& Prothero, A. (2008) Green consumption life-politics, risk and contradictions. Journal of Consumer Culture, 8(1), 117-145.

Faurschou, G. (1987) Fashion and the cultural logic of postmodernity. Canadian Journal of Political and Social Theory, 11(1-2), 68-82.

Fletcher, K. (2008) Sustainable Fashion and Textiles: Design Journeys. Earthscan/James \& James, London.

Fournier, S. (1998) Consumer resistance: Societal motivations, consumer manifestations, and implications in the marketing domain. Advances in Consumer Research, 25(1), 88-90.

Glaser, B.G. \& Strauss, A.L. (1967) The Discovery of grounded theory: Strategies for qualitative research. Aldine de Gruyter, New York.

Ha-Brookshire, J.E. \& Hodges, N.N. (2009) Socially responsible consumer behavior? Exploring used clothing donation behavior. Clothing and Textiles Research Journal, 27(3), 179-196.

Holt, D.B. (2002) Why do brands cause trouble? A dialectical theory of consumer culture and branding. Journal of Consumer Research, 29(1), 70-90.

Jackson, T. (2005) Live better by consuming less?: Is there a "double dividend” in sustainable consumption?. Journal of Industrial Ecology, 9(1-2), 19-36.

Kozinets, R.V. (2010) Netnography: Doing ethnographic research online. Sage Publications, London.

Kozinets, R.V. \& Handelman, J.M. (2004) Adversaries of consumption: Consumer movements, activism, and ideology. Journal of Consumer Research, 31(3), 691-704.

Kozinets, R.V., Belz, F. \& McDonaugh, P. (2011) Social media for social change In: Transformative Consumer Research for Personal and Collective Well-being (ed. by D.G. Mick, S. Pettigrew, C. Perchmann \& J.L. Ozanne), pp. 205-212. Routledge, New York.

Laitala, K., Boks, C. \& Klepp, I.G. (2011) Potential for environmental improvements in laundering. International Journal of Consumer Studie,s 35(2), 254-264.

Lincoln, Y.S. \& Guba, E.G. (1985). Naturalistic Inquiry, Vol. 75. Sage, London.

Luedicke, M.K., Thompson, C.J. \& Giesler, M. (2010) Consumer identity work as moral protagonism: How myth and ideology animate a brand-mediated moral conflict. Journal of Consumer Research, 36(6), 1016-1032.

Lury, C. (1996) Consumer Culture. Rutgers University Press, New Brunswick.

Marsh, P.C., Eckert, C. \& Potter, S. (2010) Consumer behavior towards sustainability in France. Proceedings, International Conferenceon Kansei Engineering and Emotion Research, March, Paris.

McCracken, G. (1986) Culture and consumption: A theoretical account of the structure and movement of the cultural meaning of consumer goods. Journal of Consumer Research, 13(1), $71-84$.

McDonough, W. \& Braungart, M. (2002) Cradle to cradle: Remaking the way we make things. North Point Press, New York. 
Mikkonen, I., Vicdan, H. \& Markkula, A. (2014) What not to wear. Oppositional idealogy, fashion and governmentality in wardrobe self help. Consumption Markets and Culture, 17(3), 254-273.

Moisander, J. (2007) Motivational complexity of green consumerism. International Journal of Consumer Studies, 31(4), 404-409.

Murray, J. (2002) The politics of consumption: A re-inquiry on thompson and haytko's (1997) “Speaking of Fashion” Journal of Consumer Research, 29, 427-439.

Marion, G., \& Nairn, A. (2011) "We make the shoes, you make the story” Teenage girls' experiences of fashion: Bricoloage, tactic and narrative identity. Consumption, Markets and Culture, 14(1), 29-56.

Ostberg, J. (2012)Masculinity and fashion. In: Gender, Culture, and Consumer Behavior (ed. by C.C. Otnes \& L.T. Zayer), pp. 255-283. Routledge, New York.

Portwood-Stacer, L. (2012) Anti-consumption as tactical resistance: Anarchists, subculture, and activist strategy. Journal of Consumer Culture, 12(1), 87-105.

Princen, T. (2005) The roogic of sufficiency. MIT Press, Cambridge.

Sanne, C. (2002) Willing consumers - or locked-in? Policies for a sustainable consumption. Ecological Economics, 42(1), 273-287.

Schaefer, A. \& Crane, A. (2005) Addressing sustainability and consumption. Journal of Macromarketing, 25(1), 76-92.

Seyfang, G. (2011) The new economics of sustainable consumption: Seeds of change, reprint. Palgrave Macmillan, London.

Shim, S. (1995) Environmentalism and consumers' clothing disposal patterns: An exploratory study. Clothing and Textiles Research Journal, 13(1), 38-48.

Smizgin, I. \& Carrigan, M. (2005) Exploring the dimensions of ethical consumption. Advances in Consumer Research, 7, 608-613.

Solomon, M.P. \& Rabolt, N.J. (2004) Consumer behavior in fashion. Pearson, Upper Saddle River.

Soper, K. (2007) Re-thinking the good life. The citizenship dimension of consumer disaffection with consumerism. Journal of Consumer Culture, 7(2), 205-229.

Starr, M.A. (2009) Does money matter in the CIS? Effects of monetary policy on output and prices. Journal of Comparative Economics, 33(3), 441-461.

Stern, P., Dietz, T. \& Guagnano, G. (1995) The new ecological paradigm in socialpsychological context. Environment and Behavior, 27, 723-743.

Thøgersen, J. (2010) Pro-environmental consumption. In: Consumer Behaviour: A Nordic Perspective (ed. by K. Ekstrom), pp. 95-116. Studentlitteratur AB, Lund.

Thomas, S. (2008) From green blur to ecofashion: Fashioning an eco-lexicon. Fashion Theory: The Journal of Dress, Body \& Culture, 12(4), 525-540. 
Thompson, C.J. \& Arsel, Z. (2004) The Starbucks brandscape and consumers' (anticorporate) experiences of glocalization. Journal of Consumer Research, 31(3), 631-642.

Thompson, C.J. \& Coskuner-Balli, G. (2007) Countervailing market responses to corporate co-optation and the ideological recruitment of consumption communities. Journal of Consumer Research, 34(2), 135-152.

Thompson, C.J. \& Haytko, D.L. (1997) Speaking of fashion: Consumers' uses of fashion discourses and the appropriation of countervailing cultural meanings. Journal of Consumer Research, 24(1), 15-42. 
TABLES

Table 1: Participant characteristics

\begin{tabular}{|c|c|c|}
\hline Name & Location & Sustainable Fashion Activities \\
\hline Timothy & United States & Daily blogger on sustainable fashion \\
\hline May Anne & Australia & $\begin{array}{l}\text { Daily blogger on sustainable fashion; runs second-hand } \\
\text { tours in home city }\end{array}$ \\
\hline Chloe & UK & $\begin{array}{l}\text { Daily blogger; designs clothing for second-hand charity } \\
\text { shop }\end{array}$ \\
\hline Sandra & UK & $\begin{array}{l}\text { Maintains a frequent blog; consults on supply issues in } \\
\text { fashion }\end{array}$ \\
\hline Maura & Australia & $\begin{array}{l}\text { Student/blogger; developing international sustainable } \\
\text { fashion network }\end{array}$ \\
\hline Maria & Denmark-Spain & $\begin{array}{l}\text { Works in development; spent time in Central America } \\
\text { working with garment workers in factories }\end{array}$ \\
\hline Magda & Sweden & Student/sells handmade organic clothing online \\
\hline Marie & Japan - Canada & Daily blogger on sustainable fashion \\
\hline Shanna & United States & $\begin{array}{l}\text { Contributor to eco magazines, launching sustainable } \\
\text { jewelry line with artisans in Uganda }\end{array}$ \\
\hline Noel & Netherlands & $\begin{array}{l}\text { Developed a contest for fashion insiders to 'give up } \\
\text { fashion for a year' }\end{array}$ \\
\hline
\end{tabular}


Table 2. Overview of the themes identified

\begin{tabular}{|c|c|}
\hline Motivation & Contextual Factors \\
\hline - Consumption is sustainability's antithesis & - Distant opaque markets \\
\hline - Sustainability facilitates style & $\begin{array}{l}\text { - Reconceptualization of } \\
\text { resources }\end{array}$ \\
\hline \multirow{2}{*}{$\begin{array}{l}\text { - Sustainable fashion brings pleasure and } \\
\text { well-being }\end{array}$} & - Societal pressures to consume \\
\hline & - The knowledge conundrum \\
\hline
\end{tabular}

